This item was submitted to Loughborough's Research Repository by the author.

Items in Figshare are protected by copyright, with all rights reserved, unless otherwise indicated.

\title{
Analysis methods for fault trees that contain secondary failures
}

PLEASE CITE THE PUBLISHED VERSION

PUBLISHER

(C) IMechE / Professional Engineering Publishing

LICENCE

CC BY-NC-ND 4.0

\section{REPOSITORY RECORD}

Dunnett, Sarah J., and J.D. Andrews. 2008. "Analysis Methods for Fault Trees That Contain Secondary Failures”. figshare. https://hdl.handle.net/2134/3824. 
This item was submitted to Loughborough's Institutional Repository (https://dspace.lboro.ac.uk/) by the author and is made available under the following Creative Commons Licence conditions.

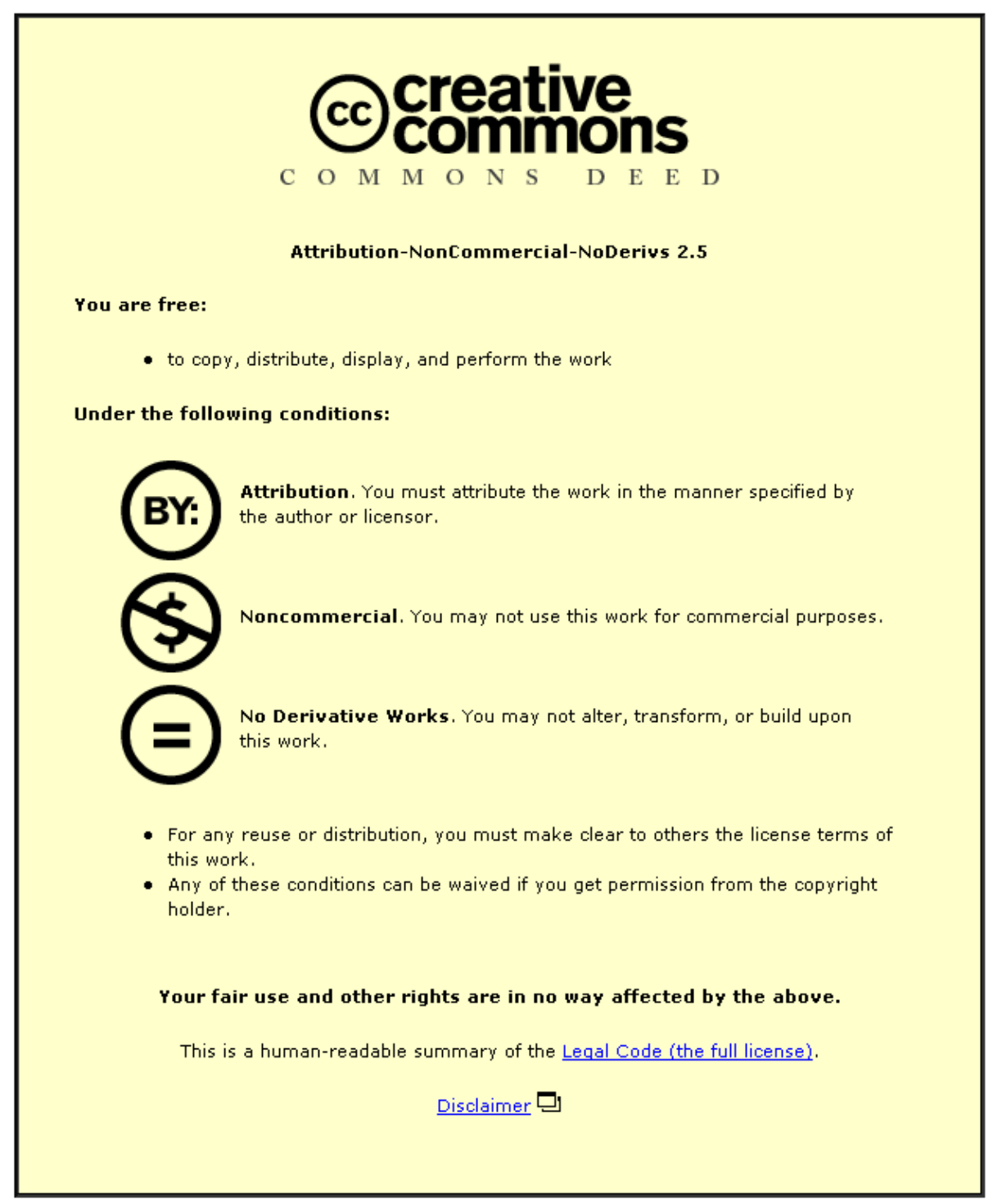

For the full text of this licence, please go to: http://creativecommons.org/licenses/by-nc-nd/2.5/ 


\title{
Analysis methods for fault trees that contain secondary failures
}

\author{
S Dunnett* and J D Andrews \\ Department of Aeronautical and Automotive Engineering, Loughborough University, Loughborough, Leicestershire, UK
}

\begin{abstract}
The fault tree methodology is appropriate when the component level failures (basic events) occur independently. One situation where the conditions of independence are not met occurs when secondary failure events appear in the fault tree structure. Guidelines for fault tree construction that have been utilized for many years encourage the inclusion of secondary failures along with primary failures and command faults in the representation of the failure logic. The resulting fault tree is an accurate representation of the logic but may produce inaccurate quantitative results for the probability and frequency of system failure if methodologies are used that rely on independence. This paper illustrates how inaccurate these quantitative results can be. Alternative approaches are developed by which fault trees of this type of structure can be analysed.
\end{abstract}

Keywords: fault tree analysis, secondary failures

\section{NOTATION}

E control system component $\mathrm{E}$ fails

$\mathrm{F}_{2} \quad$ second initiating failure event

PRV pressure relief valve failure

$q \quad$ component unavailability

$q_{C_{i}} \quad$ minimal cut set, $C_{i}$, unavailability

$q_{i}(t) \quad$ probability of the system being in state $i$ at time $t$

$Q \quad$ system unavailability

$\mathrm{T} \quad$ tank failure under normal load

$\mathrm{U} \quad$ unrevealed failure

w system failure intensity

$\mathrm{X} \quad$ control system component $\mathrm{X}$ fails

$\theta \quad$ inspection interval

$\lambda$ failure rate

$v \quad$ repair rate

$\tau \quad$ mean time to repair

\section{INTRODUCTION}

Fault tree analysis is now frequently used to assess the adequacy of systems from a reliability or availability viewpoint. The technique was originally developed in the 1960s, and guidelines were subsequently produced to describe

The MS was received on 28 April 2003 and was accepted after revision for publication on 15 December 2003.

*Corresponding author: Department of Aeronautical and Automotive Engineering, Loughborough University, Loughborough, Leicestershire, LEII 3TU, $U K$.

E01703 C IMechE 2004 how the engineering system can be modelled [1]. Modelling the system results in a representation of the failure logic which can then be quantified $[2,3]$. Model quantification produces combinations of component level failures that will cause the system failure mode (minimal cut sets), system failure probability, system failure frequency and importance measures.

It is critical that the fault tree construction process be performed accurately. Following this, there are many commercial software packages available to carry out the quantification. Rules cannot be determined that govern the construction of the failure logic diagram and guarantee the production of the correct fault tree for all circumstances. However, guidelines that provide a rigorous, systematic approach have been developed and are commonly applied by engineers. One such guideline that can be found in reference [1] is that state-of-component faults can be developed in the fault tree structure by an OR gate with primary failure, secondary failure and command faults as inputs.

This paper shows that following this process while producing correct failure logic can lead to situations where the standard means of quantifying the top event probability will be incorrect. The error occurs as the repair of individual component failures in a minimal cut set does not rectify the system state.

Two approaches are described that can be used to overcome this difficulty. The first of these employs a Markov model to analyse the sections of the fault tree where the secondary failures are located. The second method makes 
use of equations pre-determined from Markov models of basic constructs that occur in sections of the fault tree containing secondary failures. Both of these methods require the section of the fault tree to which the method is applied to be independent of the remainder of the fault tree. In the first method this is the limiting factor governing the size of the fault tree section modelled using Markov.

\section{FAULT TREE CONSTRUCTION FOR STATE-OF-COMPONENT FAULTS}

A guideline proposed for the fault tree construction process [1] was to classify events to be developed in the fault tree as either state-of component faults or state-of-system faults. The distinction between the two was based on whether the event being developed could be caused by a single component failure or not. Where the event cannot be caused by a single component failure it is classified as a state-of-system fault and developed by establishing the immediate, necessary and sufficient conditions, which usually brings an AND gate into the fault tree. If a single component failure can cause the event it is classed as a state-of-component fault and the fault tree is developed in terms of primary component failures, secondary component failures and command faults, as shown in Fig. 1.

In Fig. 1 a primary failure is defined as a component failure that occurs when the component is operating in its normal expected environment. A secondary failure is one where the component is operating outside its intended operating environment (usually owing to other failures occurring and causing an increased stress level on the component). The command fault traces the fault back into other parts of the system that provide an input to the component and could cause a working component to exhibit the fault being developed. For example, consider a control valve subsystem. To identify causes of the event where no fluid flows at the valve outlet, it is classified as a state-ofcomponent fault and developed as shown in Fig. 1. The primary component failure is the control valve itself failing closed. A command fault is a failure of the valve control system that causes a functioning valve to close.

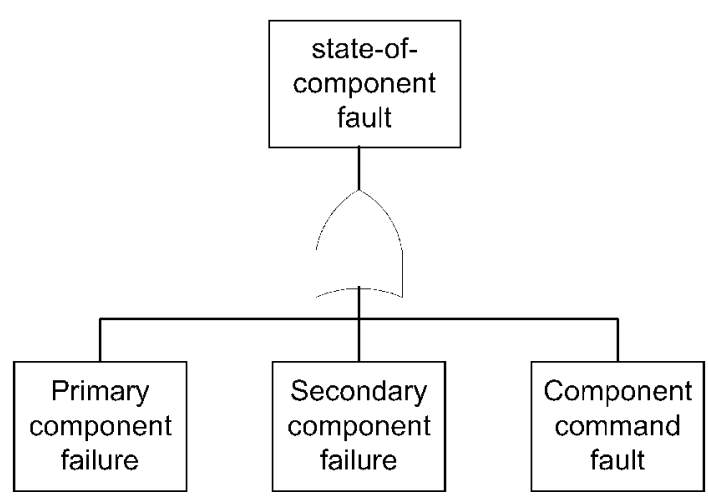

Fig. 1 Fault tree for a state-of-component fault
This approach has also been incorporated into texts that cover the fault tree method in detail $[\mathbf{2}, \mathbf{3}]$. It is an effective way of generating a fault tree with the correct failure logic and is in itself non-controversial. The potential problem comes in the later analysis stage where all basic events in the fault tree structure are assumed to occur independently. The construction of the fault tree using this guideline introduces dependencies between the repair of the basic events. A secondary failure causes the failure of another component in the system, and so the rectification of the system functionality requires the repair of more components than those that combined to cause the original problem. Failure adequately to account for this, by, for example, assuming independence between the basic events, can introduce large errors into the numerical procedures used to calculate the top event probability and frequency.

\section{PRESSURE TANK EXAMPLE}

As an example, consider the simple part of a pressure tank system illustrated in Fig. 2. The tank is filled by activating the pump. The contents are used as required by opening and closing the outlet valve. As a safety feature, in the event of overfilling, the relief valve will open to keep the pressure within acceptable bounds. It is required to predict the unavailability of the pressure tank owing to its rupture. This can be classified as a state-of-component fault since failure of the tank alone can produce this event. The fault tree is then developed accordingly.

The top Event, 'rupture of the pressure tank', is developed as illustrated in Fig. 1 and resolved into its primary and secondary causes (in this example the tank does not have a command fault). The primary failure event is that the tank fails under normal expected conditions (TANK). The secondary failure event occurs when the tank fails while operating outside its normal expected operating conditions and is caused by an overpressure situation. The overpressure that ruptures the tank (assuming overpressure will always have this outcome) is due to a pump control system failure that causes the pump to run for too long AND to the safety

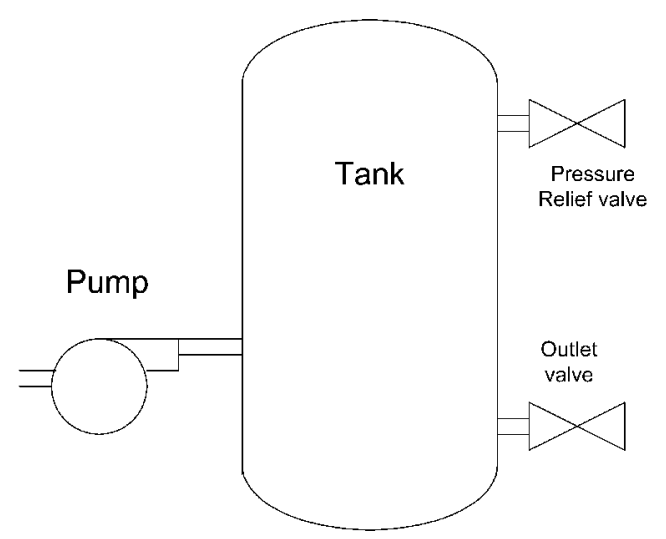

Fig. 2 Simple pressure tank system 
feature (the pressure relief valve) failing to operate. The event 'fault in control system fails to stop pump' is also a state-of-component fault and therefore developed in terms of its primary failure of $\mathrm{E}$ and secondary failure $\mathrm{X}$. The simple fault tree for this situation is represented in Fig. 3. The minimal cut sets for this fault tree are:

\section{(a) TANK, \\ (b) E. PRV, \\ (c) X. PRV.}

The implication of the qualitative analysis is that the repair of any of the events contained in a minimal cut set causing the top event will result in the system failure mode no longer existing. However, when one of the events is a secondary failure, this is no longer true. Consider minimal cut set 2 . If these two events $\mathrm{E}$ and PRV occur together, then, in addition to these two components being in the failed state, the tank will also fail. This is not an event in the minimal cut set. Considering the minimal cut set alone, if the pump or pressure relief valve are repaired it would, under conditions of independence, rectify the top event. However, since this failure is a secondary failure combination and results in tank rupture, the tank must also be repaired to rectify the system. Since the repair time of the tank is likely to be considerably longer than that of the two elements of the minimal cut set, failure to account for this in the analysis will result in a serious underestimation of the system unavailability.

It should also be noted that the pressure relief valve failure, PRV, is an enabling event [4]. i.e. one that permits another event to cause the top event. It is a failure of a safety

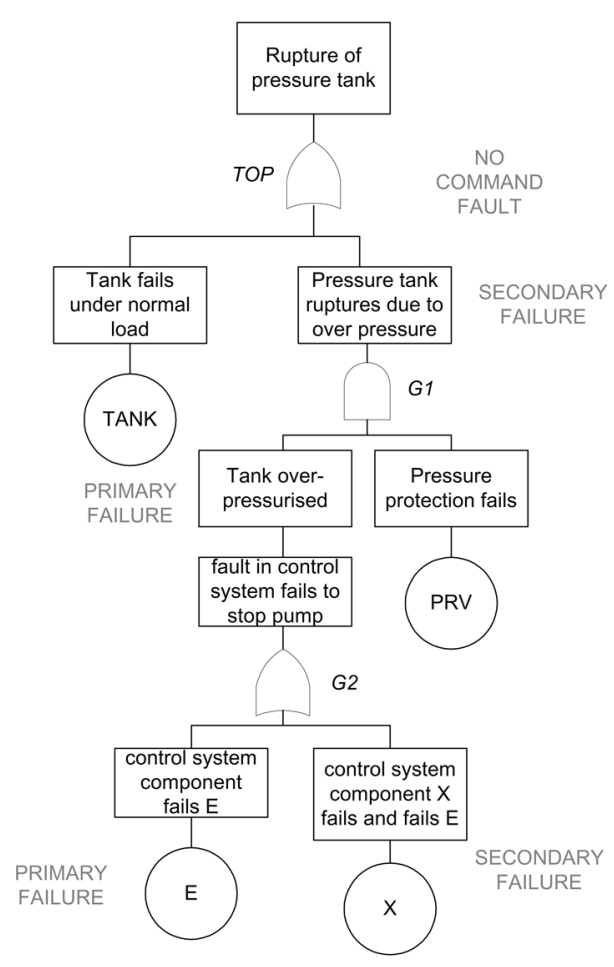

Fig. 3 Pressure tank system fault tree device that, since it is normally inactive, will, on its own, have no effect on the system unless the occurrence of an initiating event [4] puts a demand on it to work. All other events in the fault tree are initiating events whose occurrence, unless mitigated, will cause the top event.

Basic event failure and repair data are given in Table 1. A conventional analysis of the fault tree illustrated in Fig. 2 with the basic event data given in Table 1 gives a top event probability of $3.362 \times 10^{-2}$ and a top event frequency of $1.387 \times 10^{-3} \mathrm{~h}^{-1}$. A summary of the contribution to these results from each minimal cut set is given in Table 2. The full calculations are presented in Appendix 1.

These results have been obtained assuming independence of the basic events. The correct modelling of a section of the fault tree that features secondary failures would need to be performed using techniques such as the Markov methods [2] that can take into account the repair time dependence.

\section{MARKOV ANALYSIS}

Prior to performing a Markov analysis of the system, a number of assumptions are required as to how the system will be repaired. These are as follows:

1. If both $X$ and $E$ fail, PRV will be activated, revealing E. If only $\mathrm{E}$ is repaired, $\mathrm{X}$ will cause $\mathrm{E}$ to fail again, and hence both $\mathrm{E}$ and $\mathrm{X}$ are repaired.

2. If $\mathrm{E}$ or $\mathrm{X}$ fails, causing PRV to be activated, it is assumed that there is no mechanism by which PRV can subsequently fail in an inactive (stuck) mode.

3. If PRV fails first and subsequently $E$ (or X) fails, then the tank will rupture and hence PRV, E (or X) and T will need to be repaired.

4. When the repair of more than one component is to be performed, it is assumed that they will be repaired sequentially and so the repair time for all components will be the sum of their individual repair times.

The values used for these additional repair times are given in Table 3.

The Markov model for the system, which provides a direct alternative means of analysis to the fault tree in Fig. 3, is shown in Fig. 4. A list of the different states and the transitions between them is contained in Appendix 2.

In Fig. $4, \lambda_{i}$ and $v_{i}$ are the failure and repair rates for the basic events and so $i=\mathrm{E}, \mathrm{T}, \mathrm{X}$ and P. Where more than one letter appears as the subscript for the repair rate, this indicates a list of components whose repair is performed sequentially. The Markov model has been constructed in two phases to model the periodic inspection process carried out on the pressure relief valve, PRV. Phase 1 is a continuous phase that operates from $t=0$ to $t=\theta$, the inspection interval for PRV. During phase 1, a failure of this component on its own will remain unrevealed, as indicated by the ' $U$ ' defining its condition in states 5 and 8 . The failure of the relief valve in phase 1 will only be revealed by a demand on it to function (failure of $\mathrm{E}$ or $\mathrm{X}$ ). Transitions between states 
Table 1 Component failure and repair data

\begin{tabular}{lllll}
\hline $\begin{array}{l}\text { Basic event } \\
\text { code }\end{array}$ & $\begin{array}{l}\text { Failure } \\
\text { rate }\left(\mathrm{h}^{-1}\right)\end{array}$ & $\begin{array}{l}\text { Mean time } \\
\text { to repair }(\mathrm{h})\end{array}$ & $\begin{array}{l}\text { Inspection } \\
\text { interval (h) }\end{array}$ & $\begin{array}{l}\text { Type of failure: } \\
\text { dormant (enabler) } \\
\text { or revealed (initiator) }\end{array}$ \\
\hline TANK & $1 \times 10^{-7}$ & 500 & & $\mathrm{R}$ \\
PRV & $5 \times 10^{-4}$ & 25 & 1975 & $\mathrm{D}$ \\
$\mathrm{E}$ & $2 \times 10^{-3}$ & 24 & & $\mathrm{R}$ \\
$\mathrm{X}$ & $2 \times 10^{-3}$ & 24 & $\mathrm{R}$ \\
\hline
\end{tabular}

Table 2 Minimal cut set contributions to the top event

\begin{tabular}{lll}
\hline Minimal cut set & Probability $q$ & Frequency $w$ \\
\hline TANK & $4.99975 \times 10^{-5}$ & $9.9995 \times 10^{-8}$ \\
E. PRV & 0.01693 & $7.0534 \times 10^{-4}$ \\
X. PRV & 0.01693 & $7.0534 \times 10^{-4}$ \\
\hline
\end{tabular}

in this phase are indicated by a solid line in Fig. 4. Phase 2 is a discrete, instantaneous phase where the inspection takes place and reveals failures of the relief valve and transfers its status to ' $\mathrm{F}$ ' (revealed failure awaiting repair) and enables the component to be repaired as indicated by states 11 and 14. Instantaneous transitions occur every $\theta$ hours and are shown as a dotted line in Fig. 4. Phases 1 and 2 occur cyclically until the mission time is reached.

The resulting Markov model has 15 states. Examination will indicate that a more concise model could have been developed, as several states could have been merged into one. For example, states 10, 13 and 15 all feature the four components in the failed state. The model has deliberately been constructed in this way to take account of the order in which the failures occur and enable the contribution that each minimal cut set makes to the system failure to be identified. Where the occurrence of failures causes the secondary failure of another component, this is indicated by ' $(F)$ ' in the state definitions; $F_{2}$ indicates that this was the second (initiating) failure event. For this model, states 2, 6, $7,8,9,10,12,13,14$ and 15 are all failed states. The state equations for phase 1 are given by

$$
\begin{aligned}
\frac{\mathrm{d} q_{1}}{\mathrm{~d} t}= & -\left(\lambda_{\mathrm{E}}+\lambda_{\mathrm{X}}+\lambda_{\mathrm{P}}+\lambda_{\mathrm{T}}\right) q_{1}+v_{\mathrm{E}} q_{3}+v_{\mathrm{EX}} q_{4} \\
& +v_{\mathrm{P}} q_{11}+v_{\mathrm{T}} q_{2}+v_{\mathrm{TE}} q_{6}+v_{\mathrm{TEX}} q_{7}+v_{\mathrm{TP}} q_{14} \\
& +v_{\mathrm{TEP}}\left(q_{9}+q_{12}\right)+v_{\mathrm{ALL}}\left(q_{10}+q_{13}+q_{15}\right)
\end{aligned}
$$

Table 3 Component combination repair time

\begin{tabular}{lll}
\hline $\begin{array}{l}\text { Repair of } \\
\text { components }\end{array}$ & $\begin{array}{l}\text { Mean time to } \\
\text { repair } \tau(\mathrm{h})\end{array}$ & $\begin{array}{l}\text { Repair } \\
\text { rate } v\left(\mathrm{~h}^{-1}\right)\end{array}$ \\
\hline $\mathrm{E}+\mathrm{T}$ & 524 & 0.0019 \\
$\mathrm{E}+\mathrm{T}+\mathrm{X}$ & 548 & 0.0018 \\
$\mathrm{P}+\mathrm{T}$ & 525 & $1.90476 \times 10^{-3}$ \\
$\mathrm{E}+\mathrm{P}+\mathrm{T}$ & 549 & $1.8215 \times 10^{-3}$ \\
$\mathrm{E}+\mathrm{X}$ & 48 & 0.0208 \\
$\mathrm{E}+\mathrm{P}+\mathrm{X}$ & 73 & 0.0137 \\
$\mathrm{E}+\mathrm{P}$ & 49 & 0.02041 \\
$\mathrm{E}+\mathrm{P}+\mathrm{X}+\mathrm{T}$ (all) & 573 & $1.7452 \times 10^{-3}$ \\
\hline
\end{tabular}

$$
\begin{aligned}
\frac{\mathrm{d} q_{2}}{\mathrm{~d} t} & =\lambda_{\mathrm{T}} q_{1}-\left(v_{\mathrm{T}}+\lambda_{\mathrm{X}}+\lambda_{\mathrm{P}}+\lambda_{\mathrm{E}}\right) q_{2} \\
\frac{\mathrm{d} q_{3}}{\mathrm{~d} t} & =\lambda_{\mathrm{E}} q_{1}-\left(v_{\mathrm{E}}+\lambda_{\mathrm{X}}+\lambda_{\mathrm{T}}\right) q_{3} \\
\frac{\mathrm{d} q_{4}}{\mathrm{~d} t} & =\lambda_{\mathrm{X}}\left(q_{1}+q_{3}\right)-\left(\lambda_{\mathrm{T}}+v_{\mathrm{EX}}\right) q_{4} \\
\frac{\mathrm{d} q_{5}}{\mathrm{~d} t} & =\lambda_{\mathrm{P}} q_{1}+v_{\mathrm{T}} q_{8}-\left(\lambda_{\mathrm{E}}+\lambda_{\mathrm{X}}+\lambda_{\mathrm{T}}\right) q_{5} \\
\frac{\mathrm{d} q_{6}}{\mathrm{~d} t} & =\lambda_{\mathrm{E}} q_{2}+\lambda_{\mathrm{T}} q_{3}-\left(v_{\mathrm{TE}}+\lambda_{\mathrm{X}}\right) q_{6} \\
\frac{\mathrm{d} q_{7}}{\mathrm{~d} t} & =\lambda_{\mathrm{T}} q_{4}+\lambda_{\mathrm{X}} q_{2}+\lambda_{\mathrm{X}} q_{6}-v_{\mathrm{TEX}} q_{7} \\
\frac{\mathrm{d} q_{8}}{\mathrm{~d} t} & =\lambda_{\mathrm{P}} q_{2}+\lambda_{\mathrm{T}} q_{5}-\left(v_{\mathrm{T}}+\lambda_{\mathrm{X}}+\lambda_{\mathrm{E}}\right) q_{8} \\
\frac{\mathrm{d} q_{9}}{\mathrm{~d} t} & =\lambda_{\mathrm{E}}\left(q_{5}+q_{11}\right)-\left(v_{\mathrm{TEP}}+\lambda_{\mathrm{X}}\right) q_{9} \\
\frac{\mathrm{d} q_{10}}{\mathrm{~d} t} & =\lambda_{\mathrm{X}}\left(q_{5}+q_{11}\right)-v_{\mathrm{ALL}} q_{10} \\
\frac{\mathrm{d} q_{11}}{\mathrm{~d} t} & =-\left(v_{\mathrm{P}}+\lambda_{\mathrm{T}}+\lambda_{\mathrm{E}}+\lambda_{\mathrm{X}}\right) q_{11} \\
\frac{\mathrm{d} q_{12}}{\mathrm{~d} t} & =\lambda_{\mathrm{E}}\left(q_{8}+q_{14}\right)-\left(v_{\mathrm{TEP}}+\lambda_{\mathrm{X}}\right) q_{12} \\
\frac{\mathrm{d} q_{13}}{\mathrm{~d} t} & =\lambda_{\mathrm{X}}\left(q_{8}+q_{12}+q_{14}\right)-v_{\mathrm{ALL}} q_{13} \\
\frac{\mathrm{d} q_{15}}{\mathrm{~d} t} & =\lambda_{\mathrm{T}} q_{11}-\left(v_{\mathrm{TP}}+\lambda_{\mathrm{E}}+\lambda_{\mathrm{X}}\right) q_{14} q_{9}-v_{\mathrm{ALL}} q_{15} \\
&
\end{aligned}
$$

For phase 2, at $t=n \theta$ the equations for $q_{i}^{\prime}, i=5,8,11,14$, are

$$
\begin{aligned}
q_{11}^{\prime} & =q_{11}+q_{5} \\
q_{5}^{\prime} & =0 \\
q_{14}^{\prime} & =q_{14}+q_{8} \\
q_{8}^{\prime} & =0
\end{aligned}
$$

These equations were solved for $q_{i}, i=1, \ldots, 15$. The probability of system failure, the probability of the top event featured in the fault tree shown in Fig. 3, is given by

$$
\begin{aligned}
Q= & q_{2}+q_{6}+q_{7}+q_{8}+q_{9}+q_{10}+q_{12}+q_{13} \\
& +q_{14}+q_{15}
\end{aligned}
$$

and the failure intensity by

$$
w=\lambda_{\mathrm{T}}\left(q_{1}+q_{3}+q_{4}+q_{5}+q_{11}\right)+\left(q_{5}+q_{11}\right)\left(\lambda_{\mathrm{E}}+\lambda_{\mathrm{X}}\right)
$$




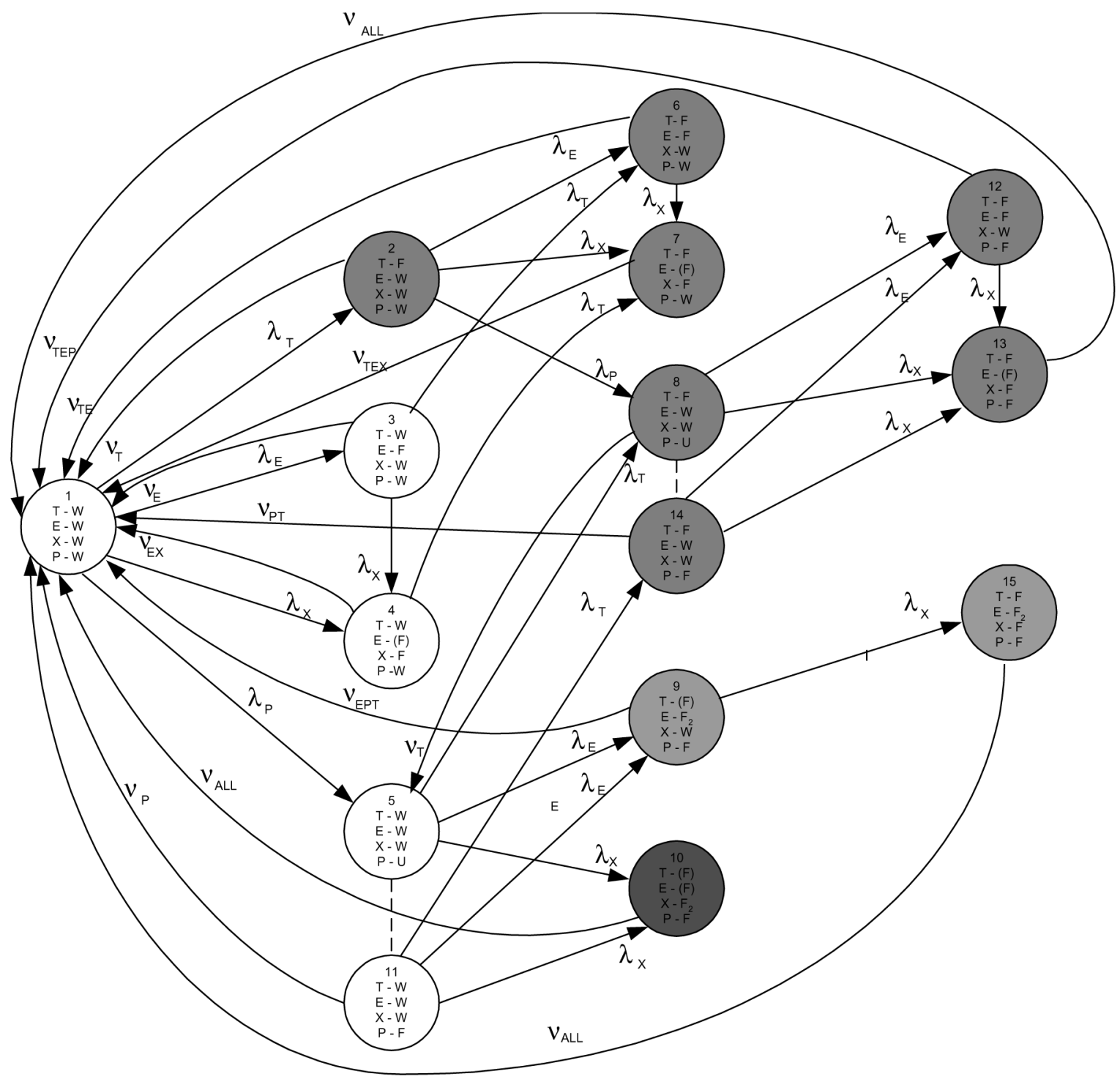

Fig. 4 System Markov state transition diagram

Results for the failure probability and failure frequency using the Markov model are contained in Table 4 and shown in Fig. 5 (averages taken over second and subsequent periods). A comparison of the Markov results with those produced by the fault tree method are also shown in Table 4. The contributions from each of the three minimal cut sets are included. It can be seen from the results in Table 4 that there is a very large error in the fault tree results.

\section{QUANTIFICATION APPROACHES FOR SECONDARY FAILURES}

It is clear from the example given above that there can be a significant error if fault trees that contain secondary failures are quantified by traditional techniques which assuming independence. The size of the error will vary depending on the fault tree structure, the failure and repair data used and the number of secondary failure events it contains.

Table 4 Comparison of Markov and fault tree results

\begin{tabular}{llllllll}
\hline & & \multicolumn{3}{c}{ Markov results } & & \multicolumn{2}{c}{ Fault tree results } \\
\cline { 3 - 6 } Event & States & Average $Q$ & Maximum $Q$ & Average $w\left(\mathrm{~h}^{-1}\right)$ & Maximum $w\left(\mathrm{~h}^{-1}\right)$ & $Q$ & \\
\hline System fails & Any minimal cut sets & 0.1652 & 0.1794 & $2.95 \times 10^{-4}$ & $3.27 \times 10^{-4}$ & 0.03362 \\
Minimal cut set 1 & $2,6,7,8,12,13,14$ & $4.425 \times 10^{-5}$ & $4.47 \times 10^{-5}$ & $8.35 \times 10^{-8}$ & $8.54 \times 10^{-8}$ & $4.99975 \times 10^{-5}$ & $9.9995 \times 10^{-8}$ \\
Minimal cut set 2 & 9,15 & 0.081 & 0.0878 & $1.4725 \times 10^{-4}$ & $1.63 \times 10^{-4}$ & 0.01693 \\
Minimal cut set 3 & 10 & 0.08425 & 0.0915 & $1.4725 \times 10^{-4}$ & $1.63 \times 10^{-4}$ & 0.01693 \\
\hline
\end{tabular}




\section{System failure probability}

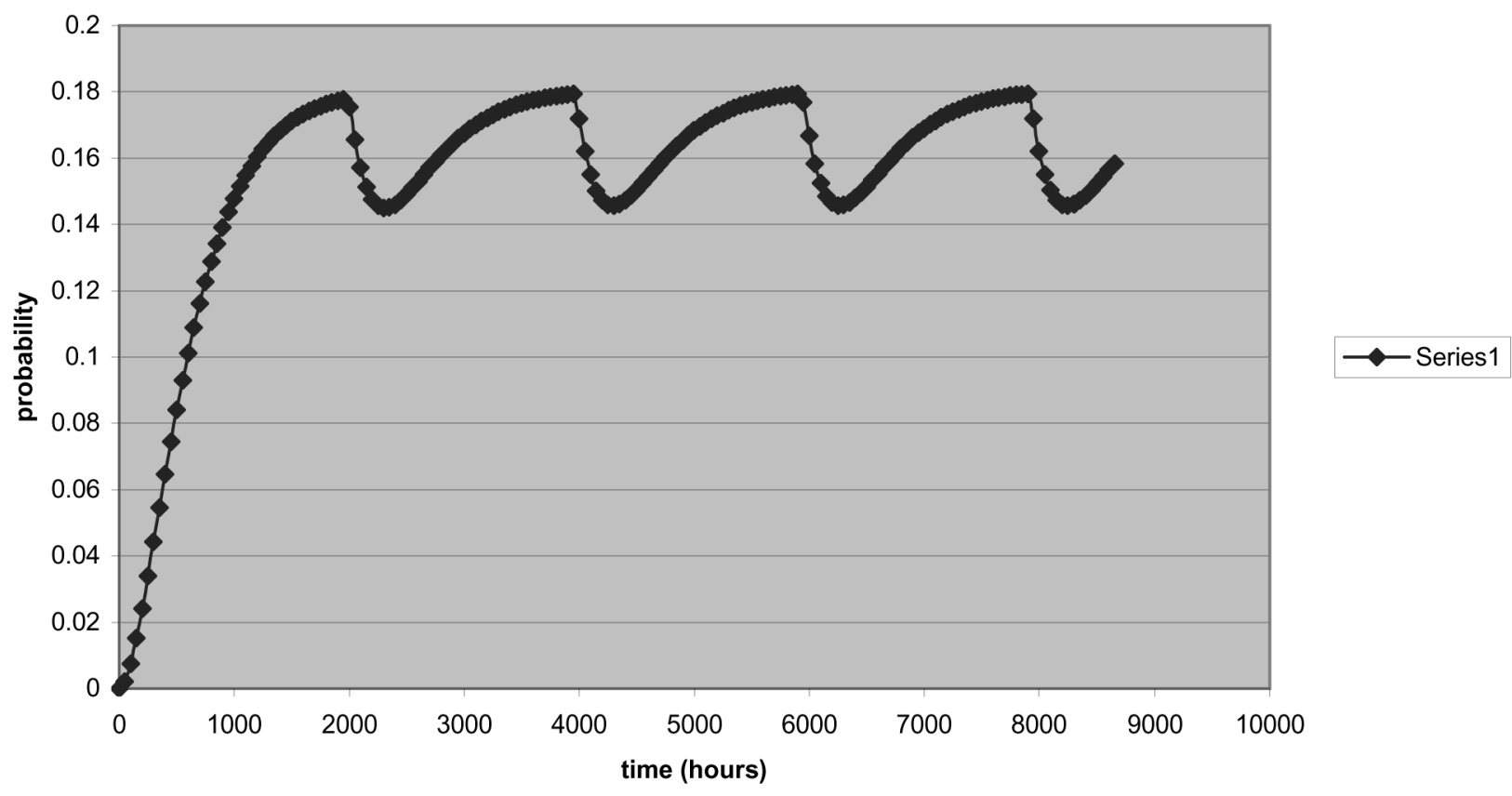

System Failure Frequency

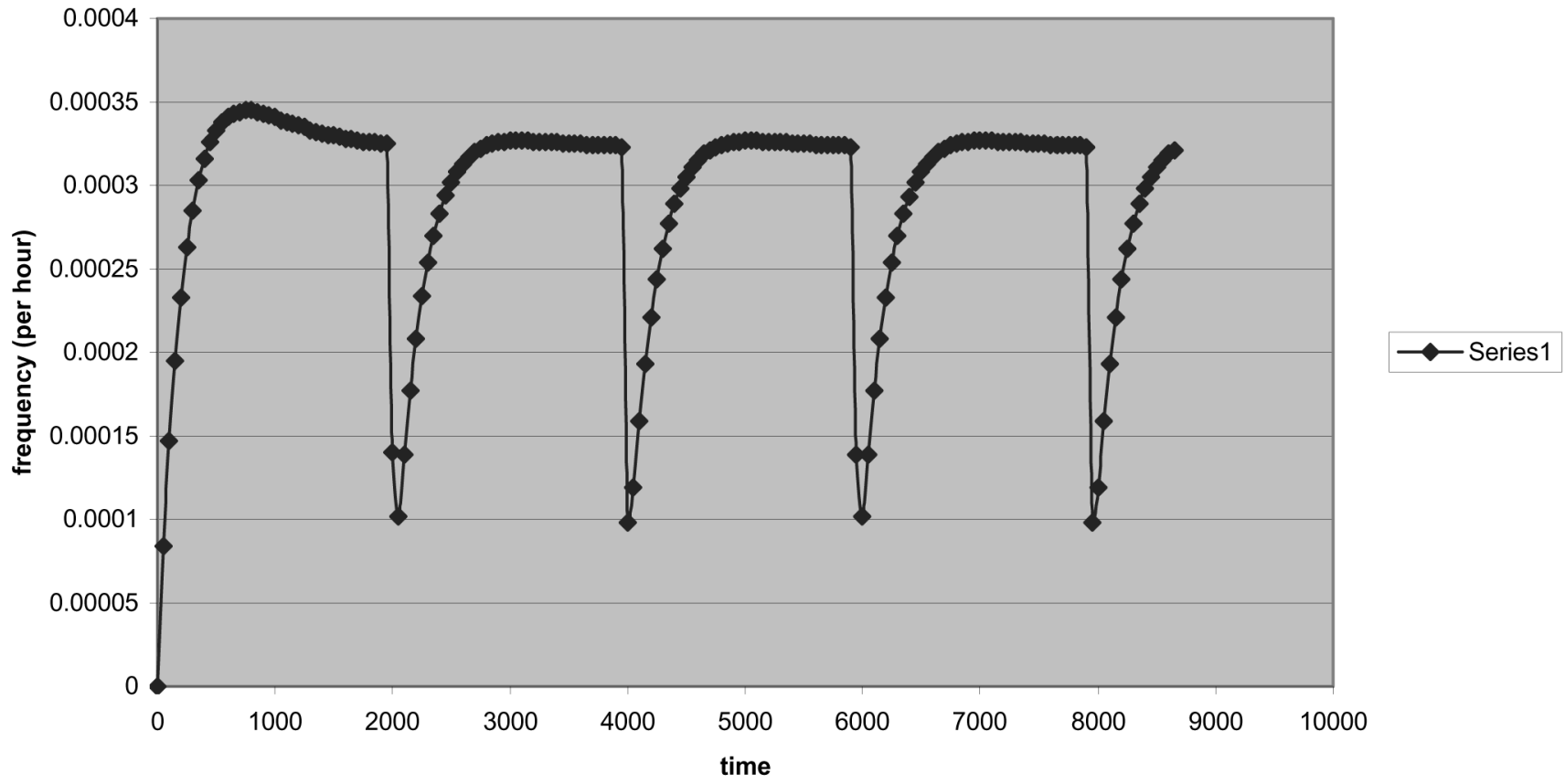

Fig. 5 System failure probability and frequency from the Markov model

Therefore, no general conclusions can be made as to when the error experienced will become significant. In the example given above, the fault tree gave an optimistic value for the system failure probability and a pessimistic failure frequency. The Markov method can be used to produce an accurate assessment for any system featuring secondary failures. However, the production of a Markov model for an entire system can require the solution of a large number of equations. The size of the Markov diagram can explode exponentially with the number of basic events and is 
inefficient for moderate to large-sized systems. Therefore, the generation of a large Markov model for the entire system does not provide an efficient solution to the problem. Two alternative approaches have been investigated:

(a) fault tree modularization methods,

(b) analysis of basic fault tree structures.

Each of these is described in the sections that follow.

\subsection{Fault tree modularization methods}

In many cases it is only a small section of the system fault tree that features the secondary failures. In these circumstances it is possible to analyse that section of the fault tree alone by the more computationally intensive Markov methods. The section of the fault tree analysed in this way is then replaced by a super-event in the fault tree structure. The failure probability and failure intensity of the superevent is derived from the Markov analysis. Analysing a section of the fault tree using the Markov approach and substituting the results back into the larger-scale analysis has become a standard way of evaluating fault trees where dependencies such as those associated with standby and sequential systems are concerned $[\mathbf{5 , 6}]$. To perform this type of analysis in an efficient way requires the section of the fault tree extracted for Markov analysis itself to be independent of the remainder of the fault tree and selected accordingly.

\subsection{Basic fault tree structures}

A common feature of fault trees that contain secondary failures is that the secondary failure section of the fault tree is itself independent of the remainder of the fault tree. In this situation it permits the use of analytical results obtained from the assessment of Markov models representing typical features of the fault tree. This removes the need to perform the numerical analysis of a larger Markov model and makes the analysis faster to compute. Consider the example fault tree shown in Fig. 3 which has two basic fault tree constructs present (as do many of this type of fault tree).
These are illustrated in Fig. 6. The fault tree section to which the method is applied must therefore be restructured in terms of the constructs illustrated. This is achieved by systematically defining complex events by pairs of basic events or other complex events occurring as inputs to the same gate type. Failure and repair parameters to the complex events are then derived as follows:

For complex events, CAND, which replace two input events $\mathrm{X}$ and $\mathrm{Y}$ into an AND gate, the failure probability, $q_{\mathrm{CAND}}$ and failure frequency, $w_{\mathrm{CAND}}$ are given by

$$
\begin{aligned}
& q_{\mathrm{CAND}}=q_{\mathrm{X}} q_{\mathrm{Y}} \\
& w_{\mathrm{CAND}}=q_{\mathrm{X}} w_{\mathrm{Y}}+q_{\mathrm{Y}} w_{\mathrm{X}}
\end{aligned}
$$

For complex events, COR, which replace two input events $\mathrm{X}$ and $\mathrm{Y}$ into an $\mathrm{OR}$ gate, the failure probability, $q_{\mathrm{COR}}$, and failure frequency, $w_{\mathrm{COR}}$, are given by

$$
\begin{aligned}
& q_{\mathrm{COR}}=1-\left(1-q_{\mathrm{X}}\right)\left(1-q_{\mathrm{Y}}\right) \\
& w_{\mathrm{COR}}=\left(1-q_{\mathrm{X}}\right) w_{\mathrm{Y}}+\left(1-q_{\mathrm{Y}}\right) w_{\mathrm{X}}
\end{aligned}
$$

Construct type 1 has two input events $\mathrm{A}$ and $\mathrm{B}$ where event $\mathrm{A}$ represents the primary failure of a component and event $\mathrm{B}$ the secondary failure. This construct type appears twice in the fault tree shown in Fig. 3 at the highest gate (TOP) and the lowest gate (G2). Construct type 2 appears where there is some protection (safety feature) that can mitigate the occurrence of a potential problem. The event that causes the potential problem, the initiating event, is event $\mathrm{C}$ in this construct. Event $\mathrm{D}$ is an enabling event, failed safety system, that permits the initiating event to cause the problem. Construct 2 is illustrated in gate G1 of the fault tree. These two basic constructs have been analysed separately using Markov models to produce equations that can be used whenever they occur in a fault tree structure. Steady state conditions are assumed to prevail at the end of each inspection cycle, as seems justified by looking at the graphs shown in Fig. 5.

By determining the probability, $q_{\mathrm{C}}$, and failure intensity, $w_{\mathrm{C}}$, for a construct, these data can then be used in a superevent replacing the construct in the fault tree. By performing this

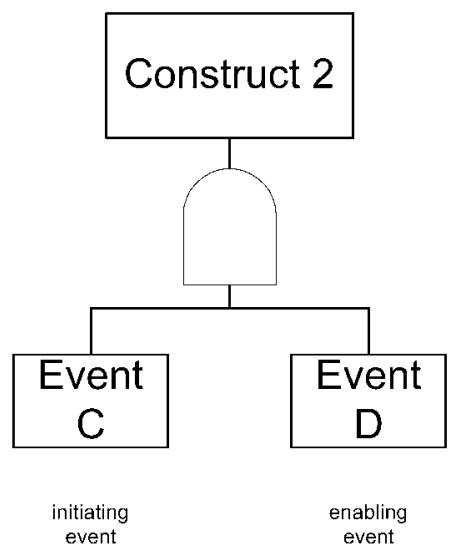

Fig. 6 Basic fault tree constructs 
type of substitution in a bottom-up manner for each gate in the fault tree, a complete assessment can be accomplished for the secondary failure section.

\subsubsection{Construct 1}

The Markov model to represent the primary and secondary failures is illustrated in Fig. 7. Here, $\lambda_{\mathrm{A}}$ and $\lambda_{\mathrm{B}}$ are the failure rates for components $\mathrm{A}$ (primary failure) and $\mathrm{B}$ (secondary failure) respectively, and $v_{\mathrm{A}}$ and $v_{\mathrm{AB}}$ are the repair rates for $\mathrm{A}$ and $\mathrm{A}$ and $\mathrm{B}$ together respectively. States 2 and 3 are failed states for this construct. The state equations for this module are

$$
\begin{aligned}
& \frac{\mathrm{d} q_{1}}{\mathrm{~d} t}=-q_{1}\left(\lambda_{\mathrm{A}}+\lambda_{\mathrm{B}}\right)+q_{2} v_{\mathrm{A}}+q_{3} v_{\mathrm{AB}} \\
& \frac{\mathrm{d} q_{2}}{\mathrm{~d} t}=q_{1} \lambda_{\mathrm{A}}-q_{2}\left(v_{\mathrm{A}}+\lambda_{\mathrm{B}}\right) \\
& \frac{\mathrm{d} q_{3}}{\mathrm{~d} t}=q_{1} \lambda_{\mathrm{B}}+q_{2} \lambda_{\mathrm{B}}-q_{3} v_{\mathrm{AB}}
\end{aligned}
$$

where $q_{i}$ is the probability of the system being in state $i$ at time $t$.

In the steady state situation solved to give $q_{1}, q_{2}, q_{3}$

$$
\begin{aligned}
q_{1} & =\frac{\left(v_{\mathrm{A}}+\lambda_{\mathrm{B}}\right) v_{\mathrm{AB}}}{\left(v_{\mathrm{AB}}+\lambda_{\mathrm{B}}\right)\left(\lambda_{\mathrm{A}}+v_{\mathrm{A}}+\lambda_{\mathrm{B}}\right)} \\
q_{2} & =\frac{v_{\mathrm{AB}} \lambda_{\mathrm{A}}}{\left(v_{\mathrm{AB}}+\lambda_{\mathrm{B}}\right)\left(\lambda_{\mathrm{A}}+v_{\mathrm{A}}+\lambda_{\mathrm{B}}\right)} \\
q_{3} & =\frac{\lambda_{\mathrm{B}}}{v_{\mathrm{AB}}+\lambda_{\mathrm{B}}}
\end{aligned}
$$

The probability of the output event of this construct occurring is determined by

$$
Q_{\mathrm{C} 1}=q_{2}+q_{3}
$$

The failure intensity for construct $1, \mathrm{w}_{\mathrm{Cl}}$, can be determined by:

$$
w_{\mathrm{C} 1}=q_{1}\left(\lambda_{\mathrm{A}}+\lambda_{\mathrm{B}}\right)
$$

\subsubsection{Construct 2}

This construct allows for the provision of safety features in the secondary failure section of the fault tree. The failure of

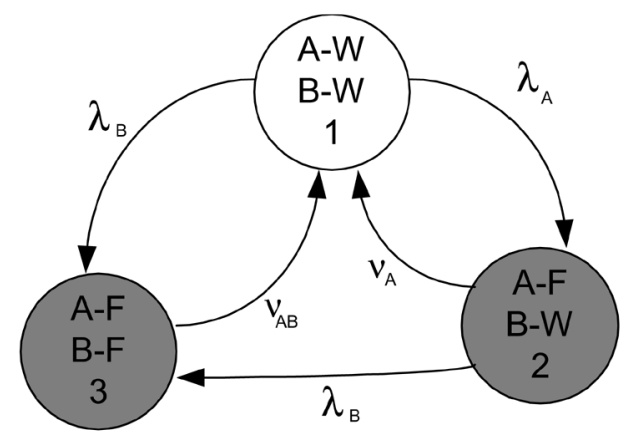

Fig. 7 Markov diagram for construct 1 the safety feature is represented by event D in Fig. 6. If this has happened and initiating event $C$ then occurs, it is unable to provide mitigation for event $\mathrm{C}$ and the failure propagates up the fault tree structure. If the initiating event occurs prior to the enabling event, failure propagation will not result. The Markov state transition diagram for this is illustrated in Fig. 8. Here, $v_{\mathrm{CD}}$ is the repair rate for events $\mathrm{C}$ and $\mathrm{D}$ together. In this case the only failed state is state 4 . The assumption is made that, once both the initiating event and the enabling event have occurred, repair will be instigated which will return both to the working state

$$
\begin{aligned}
\frac{\mathrm{d} q_{1}}{\mathrm{~d} t} & =-\left(\lambda_{\mathrm{C}}+\lambda_{\mathrm{D}}\right) q_{1}+v_{\mathrm{C}} q_{2}+v_{\mathrm{D}} q_{3}+v_{\mathrm{CD}} q_{4} \\
\frac{\mathrm{d} q_{2}}{\mathrm{~d} t} & =\lambda_{\mathrm{C}} q_{1}-v_{\mathrm{C}} q_{2} \\
\frac{\mathrm{d} q_{3}}{\mathrm{~d} t} & =\lambda_{\mathrm{D}} q_{1}-\left(v_{\mathrm{D}}+\lambda_{\mathrm{C}}\right) q_{3} \\
\frac{\mathrm{d} q_{4}}{\mathrm{~d} t} & =\lambda_{\mathrm{C}} q_{3}-v_{\mathrm{CD}} q_{4}
\end{aligned}
$$

These equations were solved for $q_{i}, i=1-5$ for the steady state situation to give

$$
\begin{aligned}
& q_{1}=\frac{\left(v_{\mathrm{D}}+\lambda_{\mathrm{C}}\right) v_{\mathrm{CD}} v_{\mathrm{C}}}{\alpha} \\
& q_{2}=\frac{v_{\mathrm{CD}}\left(v_{\mathrm{D}}+\lambda_{\mathrm{C}}\right) \lambda_{\mathrm{C}}}{\alpha} \\
& q_{3}=\frac{\lambda_{\mathrm{D}} v_{\mathrm{CD}} v_{\mathrm{C}}}{\alpha} \\
& q_{4}=\frac{\lambda_{\mathrm{C}} \lambda_{\mathrm{D}} v_{\mathrm{C}}}{\alpha}
\end{aligned}
$$

where

$$
\begin{aligned}
\alpha= & v_{\mathrm{D}} v_{\mathrm{CD}} v_{\mathrm{C}}+v_{\mathrm{CD}} \lambda_{\mathrm{C}} v_{\mathrm{D}}+v_{\mathrm{CD}} \lambda_{\mathrm{C}}^{2}+\lambda_{\mathrm{D}} v_{\mathrm{CD}} v_{\mathrm{C}} \\
& +\lambda_{\mathrm{D}} \lambda_{\mathrm{C}} v_{\mathrm{C}}+\lambda_{\mathrm{C}} v_{\mathrm{CD}} v_{\mathrm{C}}
\end{aligned}
$$

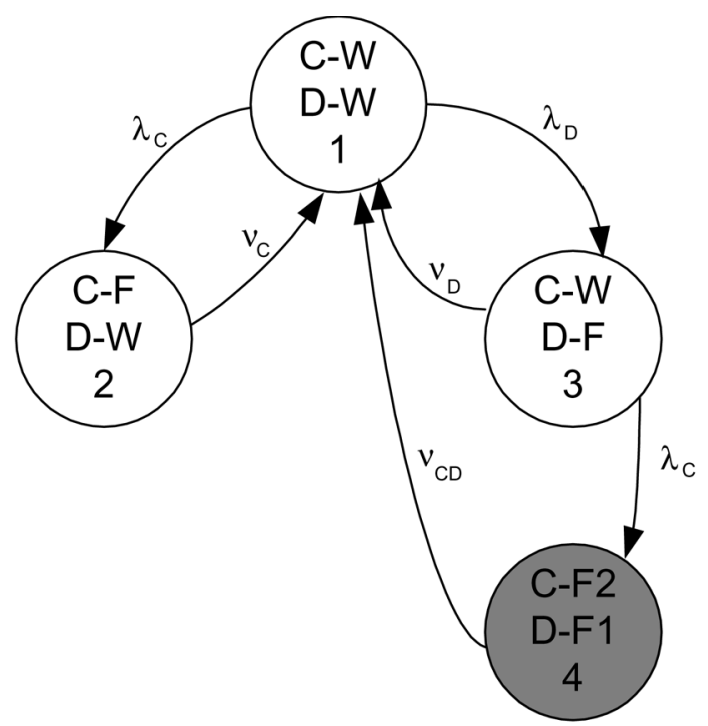

Fig. 8 Markov diagram for construct 2 
The probability, $Q_{\mathrm{C} 2}$, of the superevent replacing construct 2 is given by

$$
Q_{\mathrm{C} 2}=q_{4}
$$

The failure intensity of construct $2, w_{\mathrm{C} 2}$, is given by

$$
w_{\mathrm{C} 2}=\lambda_{\mathrm{C}} q_{3}
$$

\subsection{Application to the simple pressure tank system}

The above constructs are applied progressively up through the pressure tank failure fault tree structure illustrated in Fig. 3. The lowest gate in the structure is an OR gate with events $\mathrm{E}$ and $\mathrm{X}$ as inputs. Event $\mathrm{X}$ is a secondary failure and hence this gate type satisfies the requirements of construct 1 . Using the failure and repair data for these components and equations (1) and (2) gives

$$
\begin{aligned}
& Q_{\mathrm{G} 2}=0.12767 \\
& w_{\mathrm{G} 2}=3.4893 \times 10^{-3}
\end{aligned}
$$

Using

$$
\begin{aligned}
\lambda & =\frac{w}{1-Q} \\
v & =\frac{w}{Q}
\end{aligned}
$$

gives $\lambda_{\mathrm{G} 2}=3.999 \times 10^{-3}$ and $v_{\mathrm{G} 2}=2.733 \times 10^{-2}$.

The next gate to consider in the fault tree, gate G1, has as inputs gate $\mathrm{G} 2$ and the pressure relief valve failure (PRV). The pressure relief valve is a safety feature and thus an enabling event. Gate 2 is an initiating event that causes overpressurization and therefore puts a demand on the safety feature to respond. This satisfies the requirements of construct 2 where G2 is the initiating event and PRV is the enabler. Applying equations (3) and (4) to gate G1 yields

$$
\begin{aligned}
& Q_{\mathrm{G} 1}=0.019399 \\
& w_{\mathrm{G} 1}=3.14975 \times 10^{-4}
\end{aligned}
$$

Note that

$$
v_{\mathrm{G} 2 \mathrm{P}}=\frac{1}{\tau_{\mathrm{G} 2}+\tau_{\mathrm{P}}}=\frac{1}{36.59+25}=0.0162
$$

and therefore $\lambda_{\mathrm{Gl}}=3.212 \times 10^{-4}$ and $v_{\mathrm{G} 1}=1.6237 \times 10^{-2}$.

Finally, the top gate in the fault tree is considered. Its structure is the same as that of gate G2 and therefore the equations developed for construct 1 can be used again, with the parameters for the tank used for event A and those for gate G1 used for event B. This gives a prediction for the top event system failure of

$$
\begin{aligned}
& Q_{\text {top }}=0.15285 \\
& w_{\text {top }}=2.7219 \times 10^{-4} \mathrm{~h}^{-1}
\end{aligned}
$$

This compares well with the average Markov values of $Q_{\text {top }}=0.1652$ and $w_{\text {top }}=2.95 \times 10^{-4} \mathrm{~h}^{-1}$.

\section{CONCLUSIONS}

1. If secondary failures are to be modelled in a system failure probability assessment, accurate results will not be obtained using the fault tree analysis method. This is despite suggestions in the literature that the development of the fault tree should be conducted in a way that considers this type of failure for each state-of-component fault that occurs.

2. Markov methods will produce accurate results and can be applied to the smallest independent section of the fault tree that contains the secondary failure events. Results of this are obtained numerically and substituted back into the system fault tree to replace the section of the fault tree analysed.

3. If the part of the fault tree that contains the secondary failures contains events that are independent of the rest of the fault tree, then constructs can be applied in a bottomup manner efficiently to obtain an estimate of the top event failure parameters.

\section{REFERENCES}

1 Hassl, D. F., Roberts, N. H., Vesley, W. E. and Goldberg, F. F. Fault Tree Handbook, NUREG-0492, 1981 (US Nuclear Regulatory Commission).

2 Andrews, J. D. and Moss, T. R. Reliability and Risk Assessment, 2002 (Professional Engineering Publishing Limited, London).

3 Henley, E. J. and Kumamoto, H. Reliability Engineering and Risk Assessment, 1981, (Prentice-Hall, Englewood Cliffs, New Jersey).

4 Lambert, H. E. and Dunglinson, C. Interval reliability for initiating and enabling events. IEEE Trans. Reliability, June 1983, 32, 150-163.

5 Meshkat, L., Dugan, J. B. and Andrews, J. D. Dependability analysis of systems with on-demand and active failure modes using dynamic fault trees. IEEE Trans. Reliability, June 2002, 51(2), 240-252.

6 Meshkat, L., Dugan, J. B. and Andrews, J. D. Maintenance modelling for computer based systems. Proc. Instn Mech. Engrs, Part E: J. Process Mechanical Engineering, 2001, 215(E3), 221-233.

\section{APPENDIX 1}

\section{Fault tree quantification results}

The contributions (assuming basic event independence and that steady state conditions prevail) are given by the following. 
For minimal cut set $1\{T\}$

$$
\begin{aligned}
q_{\mathrm{C} 1} & =\frac{\lambda_{\mathrm{T}}}{\lambda_{\mathrm{T}}+v_{\mathrm{T}}}=4.99975 \times 10^{-5} \\
w_{\mathrm{C} 1} & =\lambda_{\mathrm{T}}\left(1-q_{\mathrm{C} 1}\right)=9.9995 \times 10^{-8} \mathrm{~h}^{-1}
\end{aligned}
$$

For minimal cut set $2\{E, P R V\}$

For the initiating event

$$
\begin{aligned}
q_{\mathrm{E}} & =\frac{\lambda_{\mathrm{E}}}{\lambda_{\mathrm{E}}+v_{\mathrm{E}}}=0.0458 \\
w_{\mathrm{E}} & =\lambda_{\mathrm{E}}\left(1-q_{\mathrm{E}}\right)=1.9084 \times 10^{-3} \mathrm{~h}^{-1}
\end{aligned}
$$

For the enabling event

$$
\begin{aligned}
q_{\mathrm{PRV}} & =\frac{\lambda_{\mathrm{PRV}} \theta-\left(1-\mathrm{e}^{-\lambda_{\mathrm{PRV}} \theta}\right)+\lambda_{\mathrm{PRV}} \tau_{\mathrm{PRV}}\left(1-\mathrm{e}^{-\lambda_{\mathrm{PRV}} \theta}\right)}{\lambda_{\mathrm{PRV}} \theta+\lambda_{\mathrm{PRV}} \tau_{\mathrm{PRV}}\left(1-\mathrm{e}^{-\lambda_{\mathrm{PRV}} \theta}\right)} \\
& =0.3696
\end{aligned}
$$

This gives

$$
\begin{aligned}
w_{\mathrm{C} 2} & =w_{\mathrm{E}} q_{\mathrm{PRV}}=7.0534 \times 10^{-4} \mathrm{~h}^{-1} \\
q_{\mathrm{C} 2} & =q_{\mathrm{E}} q_{\mathrm{PRV}}=0.01693
\end{aligned}
$$

For minimal cut set $3\{X, P R V\}$

For the initiating event

$$
\begin{aligned}
q_{\mathrm{X}} & =\frac{\lambda_{\mathrm{X}}}{\lambda_{\mathrm{X}}+v_{\mathrm{X}}}=0.0458 \\
w_{\mathrm{X}} & =\lambda_{\mathrm{X}}\left(1-q_{\mathrm{X}}\right)=1.9084 \times 10^{-3} \mathrm{~h}^{-1}
\end{aligned}
$$

\begin{tabular}{|c|c|c|c|c|c|}
\hline $\begin{array}{l}\text { State } \\
\text { number }\end{array}$ & $\begin{array}{l}\text { Component } \\
\mathrm{T}\end{array}$ & $\begin{array}{l}\text { Component } \\
\text { E }\end{array}$ & $\begin{array}{l}\text { Component } \\
\text { X }\end{array}$ & $\begin{array}{l}\text { Component } \\
\text { PRV }\end{array}$ & System \\
\hline 1 & W & W & W & W & W \\
\hline 2 & $\mathrm{~F}$ & W & W & W & $\mathrm{F}(\mathrm{C} 1)$ \\
\hline 3 & W & $\mathrm{F}$ & W & W & W \\
\hline 4 & W & (F) & $\mathrm{F}$ & W & W \\
\hline 5 & W & W & W & $\mathrm{U}$ & W \\
\hline 6 & $\mathrm{~F}$ & $\mathrm{~F}$ & W & W & $\mathrm{F}(\mathrm{C} 1)$ \\
\hline 7 & F & (F) & F & W & $\mathrm{F}(\mathrm{C} 1)$ \\
\hline 8 & $\mathrm{~F}$ & W & W & $\mathrm{U}$ & $\mathrm{F}(\mathrm{C} 1)$ \\
\hline 9 & (F) & $\mathrm{F}_{2}$ & W & U & $\mathrm{F}(\mathrm{C} 2)$ \\
\hline 10 & (F) & (F) & $F_{2}$ & U & F (C3) \\
\hline 11 & W & W & W & $\mathrm{F}$ & W \\
\hline 12 & F & F & W & U & $\mathrm{F}(\mathrm{C} 1)$ \\
\hline 13 & $\mathrm{~F}$ & (F) & $\mathrm{F}$ & $\mathrm{U}$ & $\mathrm{F}(\mathrm{C} 1)$ \\
\hline 14 & $\mathrm{~F}$ & W & W & $\mathrm{F}$ & $\mathrm{F}(\mathrm{C} 1)$ \\
\hline 15 & (F) & $\mathrm{F}_{2}$ & F & $F_{1}$ & $\mathrm{~F}(\mathrm{C} 2)$ \\
\hline
\end{tabular}

For the enabling event

$$
\begin{aligned}
q_{\mathrm{PRV}} & =\frac{\lambda_{\mathrm{PRV}} \theta-\left(1-\mathrm{e}^{-\lambda_{\mathrm{PRV}} \theta}\right)+\lambda_{\mathrm{PRV}} \tau_{\mathrm{PRV}}\left(1-\mathrm{e}^{-\lambda_{\mathrm{PRV}} \theta}\right)}{\lambda_{\mathrm{PRV}} \theta+\lambda_{\mathrm{PRV}} \tau_{\mathrm{PRV}}\left(1-\mathrm{e}^{-\lambda_{\mathrm{PRV}} \theta}\right)} \\
& =0.3696
\end{aligned}
$$

This gives

$$
\begin{aligned}
w_{\mathrm{C} 3} & =w_{\mathrm{X}} q_{\mathrm{PRV}}=7.0534 \times 10^{-4} \mathrm{~h}^{-1} \\
q_{\mathrm{C} 3} & =q_{\mathrm{X}} q_{\mathrm{PRV}}=0.01693
\end{aligned}
$$

The system parameters are then obtained from

$$
\begin{aligned}
Q_{\mathrm{sys}} & =1-\prod_{i=1}^{n}\left(1-q_{\mathrm{C} i}\right)=0.03362 \\
w_{\mathrm{sys}} & =\sum_{i=1}^{n}\left(w_{c i} \prod_{\substack{j=1 \\
j \neq i}}^{n}\left(1-q_{\mathrm{cj}}\right)\right) \\
& =1.3868 \times 10^{-3} \mathrm{~h}^{-1}
\end{aligned}
$$

\section{APPENDIX 2}

Markov model states

Transitions between states for the full fault tree

\begin{tabular}{lclcrl}
\hline State $i$ & State $j$ & & State $i$ & State $j$ & \\
\hline 1 & 2 & $\lambda_{\mathrm{T}}$ & 7 & 1 & $v_{\mathrm{TEX}}$ \\
1 & 3 & $\lambda_{\mathrm{E}}$ & 8 & 5 & $v_{\mathrm{T}}$ \\
1 & 4 & $\lambda_{\mathrm{X}}$ & 8 & 12 & $\lambda_{\mathrm{E}}$ \\
1 & 5 & $\lambda_{\mathrm{P}}$ & 8 & 13 & $\lambda_{\mathrm{X}}$ \\
2 & 1 & $v_{\mathrm{T}}$ & 9 & 1 & $v_{\mathrm{EPT}}$ \\
2 & 6 & $\lambda_{\mathrm{E}}$ & 9 & 15 & $\lambda_{\mathrm{X}}$ \\
2 & 7 & $\lambda_{\mathrm{X}}$ & 10 & 1 & $v_{\mathrm{ALL}}$ \\
2 & 8 & $\lambda_{\mathrm{P}}$ & 11 & 1 & $v_{\mathrm{P}}$ \\
3 & 1 & $v_{\mathrm{E}}$ & 11 & 9 & $\lambda_{\mathrm{E}}$ \\
3 & 4 & $\lambda_{\mathrm{X}}$ & 11 & 10 & $\lambda_{\mathrm{X}}$ \\
3 & 6 & $\lambda_{\mathrm{T}}$ & 11 & 14 & $\lambda_{\mathrm{T}}$ \\
4 & 1 & $v_{\mathrm{EX}}$ & 12 & 1 & $v_{\mathrm{TEP}}$ \\
4 & 7 & $\lambda_{\mathrm{T}}$ & 12 & 13 & $\lambda_{\mathrm{X}}$ \\
5 & 8 & $\lambda_{\mathrm{T}}$ & 13 & 1 & $v_{\mathrm{ALL}}$ \\
5 & 9 & $\lambda_{\mathrm{E}}$ & 14 & 1 & $v_{\mathrm{TP}}$ \\
5 & 10 & $v_{\mathrm{X}}$ & 14 & 12 & $\lambda_{\mathrm{E}}$ \\
6 & 1 & $v_{\mathrm{TE}}$ & 14 & 13 & $\lambda_{\mathrm{X}}$ \\
6 & 7 & $\lambda_{\mathrm{X}}$ & 15 & 1 & $v_{\mathrm{ALL}}$ \\
\hline
\end{tabular}

